\title{
Indicador de sustentabilidade dos agroecossistemas: estudo de caso em áreas de cultivo de milho
}

\author{
Sustainability indicator of agroecosystems: a case study in areas of maize cultivation
}

\author{
Adinor José Capellesso' ${ }^{I}$ Ademir Antonio Cazella ${ }^{I I}$
}

\section{RESUMO}

\begin{abstract}
O objetivo deste trabalho é avaliar a eficiência energética de sistemas de produção de milho convencional e orgânico em unidades produtivas do Extremo Oeste Catarinense. Os resultados do estudo de caso apontam que a produção dos híbridos transgênicos e convencionais tem uso intensivo de insumos, alcançando maior produtividade que o sistema orgânico. A conversão dos insumos em energia demonstra a baixa de eficiência energética. Com diferentes níveis de mecanização e adoção de tecnologia, o principal fator responsável pelas entradas energéticas é o uso de adubos nitrogenados de síntese química. As áreas com sistemas de produção orgânica apresentam maior eficiência energética, sendo conduzidas em pequena escala $e$ obtendo menor produtividade.
\end{abstract}

Palavras-chave: agricultura, sistema, transgênico, orgânico, agroecologia.

\section{ABSTRACT}

The aim of this paper is to analyze the energy efficiency of conventional and organic maize production systems in production units of Far West region of Santa Catarina, Brazil. The results of case study showed that the production of conventional and transgenic hybrids has intensive use of inputs and achieve greater productivity compared with the organic system. The conversion of inputs into energy showed low energy efficiency. With different levels of mechanization and technology adoption, the main factor responsible for the input energy is the use of nitrogen fertilizers chemical synthesis. The areas with organic production systems present higher energy efficient, being conducted only on a small scale and achieving average productivity.

Key words: agriculture, system, transgenic, organic, agroecology.

\section{INTRODUÇÃO}

O aumento da produtividade agropecuária se sustenta na incorporação de insumos e técnicas produtivas, sendo muitos deles degradantes da natureza e da saúde humana. Essa preocupação alimentou o desejo de desenvolver sistemas produtivos menos degradantes (agricultura sustentável), o que resultou no surgimento de várias correntes de produção de base ecológica. Essas escolas desenvolveram e aprimoraram técnicas que atendem - ao menos parcialmente - as preocupações ambientais, sociais e com a saúde humana. A incorporação dessa concepção no meio científico refletiu no surgimento da agroecologia enquanto ciência interdisciplinar, lançando olhares interconectados sobre o espaço rural e agrícola. A perspectiva agroecológica busca entender melhor os problemas inerentes às práticas agrícolas atualmente adotadas e criar inovações técnicas que contribuam na busca da agricultura sustentável em sentido amplo, ou seja, contemplando parâmetros econômicos, sociais, ambientais, éticos, culturais e energéticos (ODUM, 1988; PRIMAVESI, 1997; GLIESSMAN, 2000; ALTIERI, 2001; COLBORN et al., 2002; CAPORAL \& COSTABEBER, 2004; LOPES \& LOPES, 2011).

$\mathrm{Na}$ agricultura convencional atual, a maior quantidade de insumos tem possibilitado produzir mais por trabalhador e por área, mas a quantidade de produto obtido por unidade de energia utilizada diminuiu. Essa perda de eficiência energética (EE) tem

\footnotetext{
Instituto Federal de Educação, Ciência e Tecnologia de Santa Catarina (IFSC), 89900-000, São Miguel do Oeste, SC, Brasil. E-mail: adinor.capellesso@ifsc.edu.br. Autor para correspondência.

IPrograma de Pós-graduação em Agroecossistemas, Universidade Federal de Santa Catarina (UFSC), Florianópolis, SC, Brasil. Recebido 03.08.12 Aprovado 27.05.13 Devolvido pelo autor 13.09.13 CR-2012-0634.R1
} 
correlação positiva com a implantação de sistemas de produção intensivos e degradantes. Enquanto a energia fóssil tornava-se a base da estrutura produtiva convencional durante o Século XX, estudos passaram a destacar a perda de eficiência energética e a necessidade de analisá-la como indicador de sustentabilidade dos agroecossistemas (PIMENTEL \& PIMENTEL, 1979; COMITRE, 1995; CARMO et al., 1998; CAMPOS \& CAMPOS, 2004; GAZZONI et al., 2005; PIMENTEL et al., 2005; MELO et al., 2007; QUADROS \& KOKUSZKA, 2007).

A EE calcula a razão entre a quantidade de energia produzida (saída) por unidade utilizada (entrada) na produção: $\mathrm{EE}=\sum$ saídas/ $\sum$ entradas (MELO et al., 2007). A análise global inclui todos os insumos e operações utilizados na produção. Calcula-se, ainda, a relação entre as saídas e as entradas de fatores produtivos obtidos com energias fósseis, qualificando a análise de sustentabilidade frente ao uso de energias não renováveis. A avaliação é enriquecida com a identificação das principais fontes de energia utilizadas, apontando-se os pontos de ineficiência a serem corrigidos nas três etapas de transição agroecológica: $1^{a}$ ) aumento da eficiência no uso de insumos e técnicas; $2^{\text {a }}$ ) substituição de insumos e técnicas; e 3 3 a) redesenho dos agroecossistemas (CAPORAL \& COSTABEBER, 2004).

O presente trabalho avaliou a eficiência energética de sistemas de produção de milho convencional e orgânico em unidades produtivas (UPs) do Extremo Oeste Catarinense. Essa região se destaca pela forte presença da agricultura familiar, caracterizando-se pela adoção de sistemas de produção intensivos. Como a cultura do milho assume papel relevante nas UPs de sistema convencional e compõe o rol de cultivos presentes nas UPs de sistema orgânico, optou-se por comparar as unidades que utilizam essa cultura. Os dados de entradas e saídas levantados nas 14 propriedades foram convertidos em energia, segundo os valores de referência indicados na bibliografia. Em seguida, avaliou-se o uso das diferentes fontes de energia e calculou-se a eficiência energética.

\section{MATERIAL E MÉTODOS}

O trabalho adotou o recorte metodológico do estudo de caso, sendo conduzido na safra 2011/12 em 14 UPs da Região do Extremo Oeste Catarinense municípios de Bandeirantes, Barra Bonita, Descanso, Guaraciaba e São Miguel do Oeste. Selecionadas ao acaso, compararam-se: sete áreas de produção de milho híbrido transgênico (Bt); quatro de híbridos convencionais; e três de variedades melhoradas de polinização aberta, conduzidas em sistema orgânico.

Nas UPs de estudo foram levantados todos os insumos e práticas por meio de entrevistas estruturadas, os quais foram, depois, convertidos em energia para fins de comparação em uma mesma unidade (Megacaloria). A emergência desuniforme exigiu replantio em uma gleba de produção orgânica, sendo, nesse caso, considerados os fatores utilizados nos dois preparos e semeaduras. A mensuração das áreas de cultivo se deu por meio do uso de um equipamento de 'Global Positioning System' - GPS (erro de $\pm 3 \mathrm{~m}$ ). As análises de solo foram utilizadas para verificar se a adubação utilizada está de acordo com as reais condições de fertilidade dos solos. As semeaduras ocorreram de forma distribuída em dois meses (set./out.), todas dentro do período de Zoneamento Agroclimático da cultura do milho para a região. Por se tratar de uma comparação global entre os sistemas produtivos, desconsideraram-se as diferenças entre as datas de semeadura nas áreas. Para a análise das médias obtidas, utilizou-se o teste de Duncan (5\%), rodado no programa SANEST (ZONTA \& MACHADO, 1984), que oferece suporte para comparação de tratamentos com diferentes números de repetição.

A conversão dos insumos e práticas em energia (caloria) se orientou na bibliografia, sendo calculada e adaptada para as condições da pesquisa, tanto para entradas (fatores necessários para a produção) quanto para saídas (produção de grãos). As entradas foram classificadas em diferentes tipos de energia, listadas a seguir e descritas nos parágrafos subsequentes: a) biológica: trabalho humano e animal, material genético de propagação (semente de milho e de plantas de cobertura); b) industrial: produção das máquinas e equipamentos agrícolas; c) fóssil direta: combustíveis, lubrificantes e graxas (CARMO et al., 1988; CARMO \& COMITRE, 1991). Para enriquecer a análise, separaram-se as demais entradas em: d) fertilizantes (orgânicos e de síntese química) e corretivos; e) agrotóxicos; f) transporte da produção; e g) secagem dos grãos. As entradas foram padronizadas por unidade de área (ha) e mensuradas quanto a sua participação relativa em cada sistema produtivo (\%).

A) Energia biológica - embora alguns autores desconsiderem o trabalho humano nos cálculos de eficiência energética, contabilizaram-se as horas de trabalho na execução das tarefas. A bibliografia aponta diferentes níveis de gasto energético em decorrência do esforço de trabalho, adotando-se, no presente estudo, o valor de referência $645 \mathrm{kcal} \mathrm{h}^{-1}$ (PIMENTEL \& 
PIMENTEL, 1979). Para o trabalho animal, o padrão de conversão foi de 2400kcal h-1 (ODUM, 1967), multiplicado pelo número de animais. A produção de sementes exige diferentes níveis de intervenção, sendo por isso definido três valores de referência: milho variedade de polinização aberta $-3.500 \mathrm{kcal} \mathrm{kg}^{-1}$ (COX \& ATKINS, 1979); milho híbrido convencional $7.750 \mathrm{kcal} \mathrm{kg}^{-1}$ (COSTABEBER, 1989) e milho híbrido transgênico - 11.632,5kcal kg-1 (acréscimo de 50\% em relação ao híbrido convencional). Para adubação verde, adotaram-se $3.500 \mathrm{kcal} \mathrm{kg}^{-1}$ (o mesmo valor do milho variedade), sendo desconsiderado quando provinha de ressemeadura natural (ex.: Lolium multiflorum). Os demais fatores de produção necessários à semeadura das plantas de cobertura foram distribuídos na tabela 1 .

B) Energia industrial - no uso de máquinas e equipamentos agrícolas, adotou-se o conceito de valor adicionado, distribuindo-se a energia de fabricação durante sua vida útil. A depreciação $(\mathrm{kg}$ $\left.\mathrm{h}^{-1}\right)$ teve por base a massa $(\mathrm{kg})$ e vida útil estimada (h), seguindo-se a expressão: $\mathrm{kg} \mathrm{h}^{-1}=90 \%$ da massa $(\mathrm{kg}) /$ vida útil (h) (COSTABEBER, 1989; PACHECO, 2000). Para a produção de cada unidade de massa desses equipamentos, consideraram-se $16.690 \mathrm{kcal}$ $\mathrm{kg}^{-1}$ para tratores e colheitadeiras e $13.670 \mathrm{kcal}$ $\mathrm{kg}^{-1}$ para implementos agrícolas não motorizados
(MACEDÔNIO \& PICCHIONI, 1985). Esses valores foram multiplicados pela massa depreciável para obter-se o gasto energético por hora de uso na produção.

C) Energia fóssil direta - consideraram-se os usos de combustíveis, lubrificantes e graxas pelas máquinas e equipamentos no interior da propriedade. Em virtude das variações no consumo de combustível (óleo diesel), adotou-se a média informada pelos agricultores para tratores - $65 \mathrm{cv}: 3,5 \mathrm{~L} \mathrm{~h}^{-1} ; 75 \mathrm{cv}: 4,2 \mathrm{~L} \mathrm{~h}^{-1} ; 85 \mathrm{cv}$ : $5,0 \mathrm{~L} \mathrm{~h}^{-1}$; e $120 \mathrm{cv}: 8,0 \mathrm{~L} \mathrm{~h}^{-1}$ - e colheitadeiras $-16 \mathrm{~L} \mathrm{~h}^{-1}$. Realizando-se trocas de óleo lubrificante segundo as horas de trabalho, atribuíram-se os valores $0,06 \mathrm{~L}$ $\mathrm{h}^{-1}$, para tratores, e $0,1 \mathrm{~L} \mathrm{~h}^{-1}$, para colheitadeiras. Para o consumo de graxa, levou-se em consideração a recomendação de $30 \mathrm{~g} \mathrm{~h}^{-1}$ de trabalho, para implementos agrícolas, $50 \mathrm{~g} \mathrm{~h}^{-1}$, para os tratores (MACHADO et al., 2010; PACHECO, 2000) e $100 \mathrm{~g} \mathrm{~h}^{-1}$ de trabalho para as colheitadeiras (200\% da recomendação dos tratores em virtude de seu maior tamanho). Os valores de conversão adotados foram $8.150 \mathrm{kcal} \mathrm{L}^{-1}$ de gasolina (CARMO et al., 1988), 9.223 kcal L ${ }^{-1}$ de óleo diesel, 10.334kcal kg-1 de graxa e $9.218 \mathrm{kcal} \mathrm{L}^{-1}$ de óleo lubrificante (MELO et al., 2007).

D) Fertilizantes e corretivos - na conversão de fertilizantes de síntese química em

Tabela 1 - Eficiência energética (EE) em sistemas de produção de milho convencional e orgânico no Extremo Oeste Catarinense - safra 2011/12; e EE estimada para a safra 2010/11.

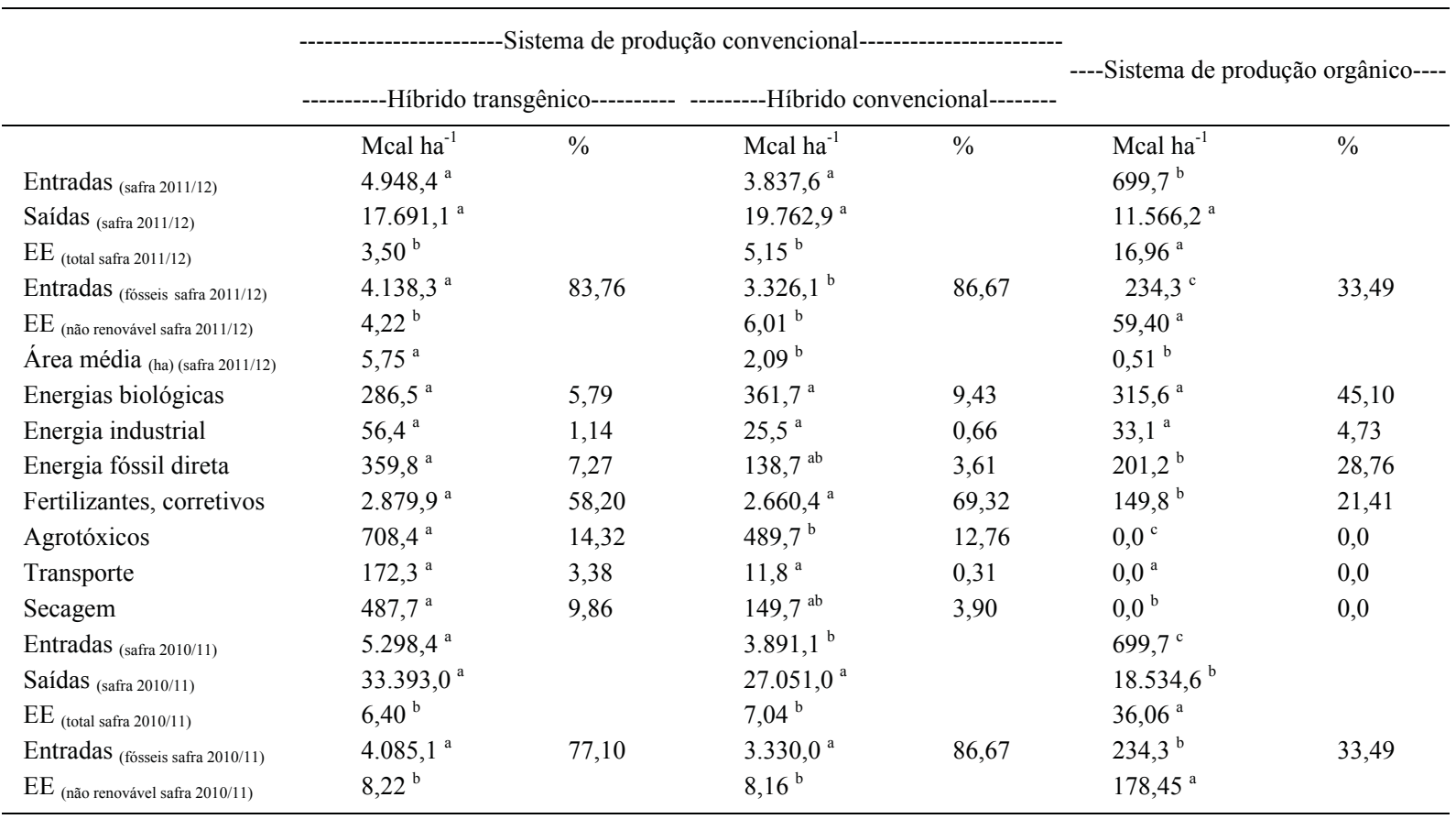

Nota: Médias seguidas por letras iguais na linha não diferem entre si no teste de Duncan: $\mathrm{P}<0,05$. 
energia, adotou-se, como base, a composição de N, $\mathrm{P}_{2} 0_{5}$ e $\mathrm{K}_{2} \mathrm{O}: 12.000 \mathrm{kcal} \mathrm{kg}^{-1}$ de $\mathrm{N}, 3.000 \mathrm{kcal} \mathrm{kg}^{-1}$ de $\mathrm{P}_{2} \mathrm{O}_{5}$ e $1.600 \mathrm{kcal} \mathrm{kg}^{-1}$ de $\mathrm{K}_{2} \mathrm{O}$ (COSTABEBER, 1989; MELO et al., 2007). O custo energético do calcário foi distribuído por três anos (efeito residual), levantando-se em consideração a média de aplicação das últimas três safras. No presente estudo adotouse $240,1 \mathrm{kcal} \mathrm{kg}^{-1}$ - o qual foi obtido pela soma de $40,1 \mathrm{kcal} \mathrm{kg}^{-1}$ utilizadas na extração e moagem da rocha (MACEDÔNIO \& PICCHIONI, 1985) e $200 \mathrm{kcal} \mathrm{kg}^{-1}$ referentes ao transporte $\left(0,88 \mathrm{kcal} \mathrm{kg}^{-1}\right.$ $\mathrm{km}^{-1}$ ) até as UPs, os quais foram considerados não renováveis. Para fertilizantes orgânicos, adotaram-se os valores propostos por SOUZA et al. (2008), sendo $15 \mathrm{kcal} \mathrm{kg}^{-1}$ para esterco bovino, $30 \mathrm{kcal} \mathrm{kg}^{-1}$ para cama de aviário, $3.000 \mathrm{kcal} \mathrm{m}^{-3}$ para dejetos suínos e $100 \mathrm{kcal} \mathrm{kg}^{-1}$ de esterco de peru peletizado (sendo esse último com valor maior por ser processado).

E) Agrotóxicos - adotou-se como base para a conversão: $99.986,0 \mathrm{kcal} \mathrm{kg}^{-1}$ para herbicida, $22.017,0 \mathrm{kcal} \mathrm{kg}^{-1}$ para fungicida e $86.976,0 \mathrm{kcal} \mathrm{kg}^{-1}$ para inseticida (MELO et al., 2007).

F) Transporte da produção - o transporte da produção foi contabilizado de duas maneiras. 1) no interior da propriedade: distribuindo-se, na tabela 1, entre os respectivos fatores utilizados: horas de trabalho animal e humano (carroça); ou horas de máquinas, consumo de combustíveis e trabalho humano (carreta agrícola). 2) externo: uso de caminhões com custo energético de $880 \mathrm{kcal} \mathrm{t}^{-1} \mathrm{~km}^{-1}$ (SOUZA et al., 2008).

G) Secagem de grãos - a secagem adotada pelos agricultores se dá de duas maneiras: ao sol (pequenos volumes) ou em silos secadores em que a lenha é empregada como fonte de energia (renovável). Para a secagem ao sol, contabilizou-se o gasto de energia em trabalho humano. A quantidade de energia para secagem artificial depende das condições climáticas e da quantidade de água presente no grão. Para adequar o gasto energético aos diferentes graus de umidade informados pelos agricultores, calculou-se a quantidade de água removida por meio da expressão: Massa de água retirada $=[(\mathrm{Ui}-\mathrm{Uf}) /(100-\mathrm{Uf})] \mathrm{XMtg}$, sendo Ui: umidade inicial; Uf: umidade final (13\%); e Mtg: massa total de grãos. Adotou-se o gasto de $1.220 \mathrm{kcal} \mathrm{kg}^{-1}$ de água removida (RIBEIRO \& VICARI, 2005).

No que diz respeito às saídas de energia, para padronizar os cálculos, levou-se em consideração a produção de grãos de milho com 13\% de umidade, adotando-se, como base para a conversão, o valor $3.844 \mathrm{kcal} \mathrm{kg}^{-1}$ (MELO et al., 2007). Os restos culturais deixados na lavoura após a colheita foram desconsiderados das saídas, uma vez que são reincorporados ao sistema.

O cálculo de EE foi realizado de duas maneiras. 1) total: pela divisão das saídas de energia pelas entradas totais; 2) não renovável: pela razão entre as saídas totais de energia e as entradas de origem fóssil. Foram classificadas como entradas não renováveis: energia industrial utilizada na fabricação de máquinas e equipamentos; combustíveis, lubrificantes e graxas; fertilizantes de síntese química $\left(\mathrm{N}, \mathrm{P}_{2} \mathrm{O}_{5}, \mathrm{~K}_{2} \mathrm{O}\right)$; calcário; agrotóxicos; e transporte da produção. Em virtude da queda de produção ocasionada pela escassez hídrica (safra 2011/12), optou-se ainda por avaliar a eficiência energética em uma condição hipotética de safra, ocorrida em ótimas condições ambientais. Com essa finalidade, adotou-se, como base, a produtividade obtida na safra 2010/11, que contou com ótima distribuição de chuvas e usos semelhantes de insumos nas mesmas áreas de produção. $\mathrm{O}$ cálculo seguiu a expressão: $\mathrm{EE}=\sum$ produtividade da safra 2010/11 (obtida em ótima distribuição de chuvas) / $\sum$ entradas da safra 2011/12 (sendo secagem e transporte adaptados para a produtividade da safra 2010/11).

\section{RESULTADOS E DISCUSSÃO}

A razão entre as entradas e saídas de energia levantadas nas UPs estudadas na safra 2011/12 indicou um elevado consumo de energia e baixa eficiência nos sistemas de produção de milho transgênico e convencional (Tabela 1). Embora utilizando áreas menores, o cultivo de milho em sistema de produção orgânico $(E E=16,96)$ apresentou maior eficiência energética que o milho híbrido transgênico $(\mathrm{EE}=3,50)$ e convencional $(\mathrm{EE}=5,15)$. Esses dados corroboram estudos anteriores que apontam a perda de EE associada ao processo de intensificação dos sistemas produtivos. $\mathrm{Na}$ expectativa de elevar a área e a produtividade, o milho transgênico tem sido conduzido em sistemas ainda mais intensivos. Os resultados encontrados são discrepantes quando comparados com os verificados por CAMPOS et al. (2004): $E E=38,21$ no sistema orgânico e $E E=21,95$ no convencional. Por sua vez, aproximamse daqueles calculados por PIMENTEL \& BURGUESS (1980) nos sistemas intensivos dos Estados Unidos - EE média de 2,47 (entre de 1,4 a 4,5).

Entre as entradas no sistema convencional, destaca-se a grande participação de energia não renovável, com emprego maior entre os híbridos transgênicos. Em termos relativos, representa $83,76 \%$, quando empregados híbridos transgênicos e $86,67 \%$ com híbridos convencionais de milho. No 
sistema orgânico, atingiu 33,49\% das entradas e, em valores absolutos (Kcal ha-1), representa somente $6,1 \%$ dos gastos de energia fóssil realizados no sistema convencional. Esses resultados refletem o processo de intensificação dos sistemas de produção, com destaque para uso de fertilizantes nitrogenados de síntese química (detalhado no parágrafo a seguir). Ao comparar a eficiência energética não renovável $\left(\mathrm{EE}_{\text {não renovável }}=\right.$ saídas/entradas fósseis $)$, o sistema orgânico $\left(\mathrm{EE}_{\text {não renovável }}=59,40\right)$ foi dez vezes mais eficiente que os híbridos transgênicos $\left(\mathrm{EE}_{\text {não renovável }}=\right.$ $4,22)$ e convencionais ( $\left.\mathrm{EE}_{\text {não renovável }}=6,01\right)$, o que indica alta eficiência no uso de energia fóssil.

Os fatores que mais contribuíram para a menor eficiência energética no sistema convencional foram os fertilizantes e corretivos, assim como verificado em sistemas intensivos nos EUA (PIMENTEL \& BURGUESS, 1980). O uso intensivo de fertilizantes nitrogenados de síntese química, associados ao alto custo energético, faz com que esse fator represente em média 48,9\% $\left(2.417,8 \mathrm{Mcal} \mathrm{ha}^{-1}\right)$ do total das entradas na produção de milho híbrido transgênico e 57,8\% (2.217,8Mcal $\mathrm{ha}^{-1}$ ) para o híbrido convencional. $\mathrm{O}$ uso médio de fertilizantes nitrogenados para o milho transgênico e convencional foi $195,4 \mathrm{~kg} \mathrm{ha}^{-1}$, ou seja, $19 \%$ superior à recomendação técnica. Se o solo possuísse baixos níveis de matéria orgânica, cultivo antecedente de gramíneas e adotasse a expectativa de colheita média dos agricultores $\left(8.922 \mathrm{~kg} \mathrm{ha}^{-1}\right)$, a recomendação técnica seria de $163,8 \mathrm{~kg} \mathrm{ha}^{-1}$ de N (COMISSÃO..., 2004). Em uma UP, utilizaram-se $267,58 \mathrm{~kg} \mathrm{ha}^{-1}$ de $\mathrm{N}$ (expectativa de $10.700 \mathrm{~kg} \mathrm{ha}^{-1}$ ), ou seja, ao menos $40 \%$ superior à recomendação técnica. Em outras UPs, a sobredosagem de adubações é reforçada pelo uso concomitante de fertilizantes orgânicos (não computados nos cálculos acima). Já nas UPs com produção de milho orgânico, as entradas de fertilizantes e corretivos foram menores que nos sistemas convencionais, representando 21,41\% $\left(149,8 \mathrm{Mcal} \mathrm{ha}^{-1}\right)$ da energia do sistema, referentes à aplicação de calcário e dejetos animais líquidos, sólidos e peletizados para uso na semeadora.

Em termos de uso de agrotóxicos, a participação nas entradas de energia diferiu entre os sistemas de produção de milho transgênico e convencional. Contrariando seus defensores, a adoção dessa tecnologia resultou em maior gasto energético com agrotóxicos quando comparado ao convencional. Já a produção orgânica não utiliza agrotóxicos e é conduzida em menor escala, o que permite a secagem ao sol e processamento no interior da propriedade. As principais entradas foram provenientes de: energias biológicas (trabalho humano e animal; sementes de milho e plantas de cobertura); e energia fóssil direta, decorrente do uso de combustíveis, lubrificantes e graxas para as máquinas e equipamentos. A tração animal é utilizada tanto em áreas de sistemas de produção convencional quanto orgânica da região, sendo o uso de máquinas também realizado em sistemas de base ecológica - não se verificando diferenças estatísticas. Embora os resultados de EE sejam animadores na produção orgânica, apontase para a necessidade de inovações que permitam ampliar as áreas de cultivo e a produtividade. Para os sistemas convencionais, destaca-se a necessidade de tecnologias que contribuam para reduzir a adubação nitrogenada de síntese química (ex. fixação biológica de nitrogênio, fertilizantes orgânicos, etc.) e substituir o uso de agrotóxicos.

As maiores entradas de energia para secagem do milho transgênico não decorrem das características do grão, mas do maior percentual da produção destinada à secagem em silos (fonte de calor a base de lenha). Esse sistema ocupa maiores áreas e a produção destina-se à criação animal, vinculada às agroindústrias da região. Como os agricultores optam por realizar duas safras de verão, a colheita é realizada normalmente com umidade superior a $20 \%$ para apressar a implantação da safrinha, reforçando a exigência de secagem artificial. Parte do milho convencional e a totalidade do milho orgânico foram utilizadas/processadas no interior da propriedade e secos ao sol (na lavoura, antes da colheita ou com grãos sobre lona), refletindo no menor consumo de energia para o transporte e secagem, embora não se verifiquem diferenças estatísticas. A quase totalidade do milho orgânico destina-se à produção de farinha (fubá), pois alcança mercados diferenciados, por não demandar agrotóxicos no seu processo produtivo.

Embora as maiores entradas energéticas no sistema convencional sejam destinadas a alcançar alta produtividade, a deficiência hídrica durante a Safra 2011/12 comprometeu a produtividade, uma vez que não foi efetuada irrigação. Utilizando dados da colheita obtida na Safra 2010/11, ano que contou com condições hídricas muito favoráveis, a EE total nos sistemas de produção de milho aumentaria de: 3,50 para 6,40 para o transgênico; 5,15 para 7,04 para o convencional; 16,96 para 36,06 para orgânico. A elevação da produtividade reflete positivamente na $\mathrm{EE}_{\text {não renovável }}$ para todos os sistemas, mantendo-se os melhores resultados para o milho orgânico.

Ciência Rural, v.43, n.12, dez, 2013. 


\section{CONCLUSÃO}

A intensificação tecnológica dos sistemas de produção agrícola permite o aumento de produtividade e o cultivo de áreas maiores, mas vem acompanhada pela redução na eficiência energética. Essa condição foi verificada para as condições de produção de milho híbrido transgênico e convencional, sendo que o uso de adubos nitrogenados de síntese química representa a principal entrada de energia nessas formas de produção. Enquanto o uso de agrotóxicos foi maior no sistema de produção de milho transgênico em relação ao convencional, a eficiência energética não diferiu entre ambos. Logo, aponta-se para a necessidade de tecnologias e práticas que contribuam para reduzir a adubação nitrogenada de síntese química e a aplicação de agrotóxicos nesses sistemas.

O sistema de produção orgânico foi o mais eficiente no uso de energia não renovável e total, quando comparado com a produção convencional de milho, o que indica melhores condições de sustentabilidade. Contudo, a produção orgânica é conduzida em pequenas áreas e por número reduzido de agricultores da região.

\section{REFERÊNCIAS}

ALTIERI, M. Agroecologia: a dinâmica produtiva da agricultura sustentável. Porto Alegre: UFRGS, 2001. 110p.

BUENO, O. de C. Análise energética e eficiência cultural do milho em assentamento rural, Itaberá/SP. 2002. 141f. Tese (Doutorado em Agronomia) - Universidade Estadual Paulista "Júlio de Mesquita Filho" (UNESP), Botucatu, SP.

CAMPOS, A.T.; CAMPOS, A.T. de. Balanços energéticos agropecuários: uma importante ferramenta como indicativo de sustentabilidade de agroecossistemas. Ciência Rural, Santa Maria. v.34, n.6, p.1977-1985, 2004. Disponível em: <http://www.scielo. $\mathrm{br} / \mathrm{scielo}$.php? pid $=\mathrm{S} 0103-84782004000600050 \& \mathrm{script}=\mathrm{sci}$ arttext>. Acesso em: 12 de junho de 2011. doi: http://dx.doi. org/10.1590/S0103-84782004000600050.

CAMPOS, A.T. et al. Balanço de energia em sistemas orgânico e convencional de produção de milho. In: ENCONTRO DE ENERGIA NO MEIO RURAL E GERAÇÃO DISTRIBUIDA, 5., 2004, Campinas, 2004. Anais... Campinas, 2004. Disponível em: $<$ http://www.feagri.unicamp.br/energia/agre2004/Fscommand/ PDF/Agrener/Trabalho\%2024.pdf>. Acesso em: 15 jul. 2012.

CAPORAL, F.R.; COSTABEBER, J.A. Agroecologia e extensão rural: contribuições para a promoção do desenvolvimento rural sustentável. Brasília: MDA/SAF/DATER: IICA, 2004. 166p.

CARMO, M.S. do et al. Balanço energético de produção na agricultura alternativa. Agricultura em São Paulo, São Paulo, v.35, n.1, p.87-97, 1998.

COLBORN, T. et al. O futuro roubado (título original: "Our stolen future"). Porto Alegre: L\&PM, 2002. 354p.
COMISSÃO DE QUÍMICA E FERTILIDADE DO SOLO - RS/ SC. Manual de Adubação e Calagem para os Estados do Rio Grande do Sul e de Santa Catarina. 10.ed. Porto Alegre: SBCSCQFS, 2004. 400p. Disponível em: <http://www.sbcs-nrs.org.br/ docs/manual_de_adubacao_2004_versao_internet.pdf $>$. Acesso em: 20 nov. $\overline{2} 01 \overline{2}$.

COMITRE, V. A questão energética e o padrão tecnológico da agricultura brasileira. Informações econômicas, São Paulo, v.25, n.12, p.29-35, 1995. Disponível em: <ftp://ftp.sp.gov.br/ftpiea/ tec2-1295.pdf>. Acesso em: 15 maio, 2012.

COSTABEBER, J.A.C. Eficiência energética e processos de produção em pequenas propriedades rurais. 1989. $295 \mathrm{f}$. Dissertação (Mestrado em Extensão Rural) - Universidade Federal de Santa Maria, RS.

COX, G.W.; ATKINS, M.D. Energy costs of agriculture. In: COX, G.W. et al. Agricultural ecology. San Francisco: Freeman and Sons, 1979. p.597- 629 .

GAZZONI, D.L. et al. Balanço energético das culturas de girassol e soja para a produção de biodiesel. Biomassa \& Energia, Viçosa, v.2, n.4, p.259-265, 2005.

GLIESSMAN, S.R. Agroecologia: processos ecológicos em agricultura sustentável. Porto Alegre: UFRGS, 2000. 653p.

LOPES, P.R.; LOPES, K.C.S.A. Sistemas de produção de base ecológica - a busca por um desenvolvimento rural sustentável. Revista Espaço de Diálogo e Desconexão, Araraquara, v.4, n.1, 2011. Disponível em: <http://seer.fclar.unesp.br/redd/article/ view/5047/4185>. Acesso em: 01 ago. 2012.

MACEDÔNIO , A.C.; PICCHIONI, S.A. Metodologia para o cálculo do consumo de energia fóssil no processo de produção agropecuária. Curitiba: DERAL/SEAB, 1985. 95p.

MACHADO, A.L.T et al. Tratores para a agricultura familiar: guia de referência. Pelotas: UFPel, 2010. 125p.

MELO, D. de, et al. Balanço energético do sistema de produção de soja e milho em uma propriedade agrícola do Oeste do Paraná. Acta Scientiarum Agronomy, Maringá, v.29, n.2, p.173-178, 2007. Disponível em: <http://periodicos.uem.br/ojs/index.php/ ActaSciAgron/article/view/233>. Acesso em: 10 de julho de 2011. doi: http://dx.doi.org/10.4025/actasciagron.v29i2.233.

ODUM, H.T. The world food problem. Washington: DC, 1967. V.2, 94p.

ODUM, E.P. Ecologia. Rio de Janeiro: Guanabara Coogan, 1988. $434 \mathrm{p}$.

PACHECO, E.P. Seleção e custo operacional de máquinas agrícolas. Rio Branco: Embrapa-Acre, 2000. 21p. (Embrapa Acre - Documentos, 58). Disponível em: <http://www.infoteca. cnptia.embrapa.br/bitstream/doc/495355/1/doc58.pdf $>$. Acesso em: 18 jul. 2012.

PIMENTEL, D.; PIMENTEL M. Food energy and society. London: Edward Arnold, 1979. 163p.

PIMENTEL, D.; BURGESS, M. Energy inputs in corn production. In: PIMENTEL, D. (Ed.). Handbook of energy utilization in agriculture. Boca Raton, Florida: CRC, 1980. p.67-84.

Ciência Rural, v.43, n.12, dez, 2013. 
PIMENTEL, D. et al. Environmental, energetic, and economic comparisons of organic and conventional farming systems. BioScience Washington, v.55, n.7, p.573-582, 2005. Disponível em: <http:// faculty.arec.umd.edu/jhanson/Environmental, $\% 20$ Energetic, $\% 20$ and $\% 20$ Economic $\% 20$ Comparisons $\% 20$ of $\% 20$ Organic $\% 20$ and $\% 20$ Conventional $\% 20$ Farming $\% 20$ Systems.pdf $>$. Acesso em: 20 de julho de 2011. doi: http://dx.doi.org/10.1641/0006-3568(2005)055[0573:EE $\mathrm{AECO} 2.0 . \mathrm{CO} ; 2$.

PRIMAVESI, A. Agroecologia: ecosfera, tecnosfera e agricultura. São Paulo: Nobel, 1997. 199p.

QUADROS, K.R. de; KOKUSKA, R. Balanço energético em sistemas de produção convencional e agroecológico de feijão, na região de Rebouças - PR. In: CONGRESSO BRASILEIRO DE AGROECOlOGIA, 2., 2007, Porto Alegre, RS. Revista Brasileira de Agroecologia, v.2, n.1. p.50-54, 2007.

RIBEIRO, I.; VICARI, C.C. Análise de viabilidade econômica para secagem de milho com gás liquefeito de petróleo. In:
SCCSASEMINÁRIO DO CENTRO DE CIÊNCIAS SOCIAIS APLICADAS, 4., 2005, Cascavel, PR. Anais... Cascavel, 2005. Disponível em: <http://www.unioeste.br/campi/cascavel/ ccsa/IVSeminario/IVSeminario/Artigos/07.pdf $>$. Acesso em: 18 jul. 2012.

SILVA, J. de S. (Ed.). Secagem e armazenagem de produtos agrícolas. 2.ed. Viçosa: Aprenda fácil, 2008. 560p.

SOUZA J.L. et al. Balanço e análise da sustentabilidade energética na produção orgânica de hortaliças. Horticultura Brasileira, Brasília, v.26, n.4. p.433-440, 2008. Disponível em: <http://www. scielo.br/pdf/hb/v26n4/v26n4a03.pdf>. Acesso em: 10 de julho de 2012. doi: http://dx.doi.org/10.1590/S0102-05362008000400003.

ZONTA, E.P.; MACHADO, A.A. SANEST - Sistema de análise estatísticas para microcomputadores. Pelotas: UFPel, 1984. 75p. 